\title{
Temperature Signals in Tree-Ring Width Chronologies of Alpine Treeline Conifers from the Baishui River Nature Reserve, China
}

\author{
Huiqin Wang ${ }^{1,2,3}$, Feng Chen ${ }^{1,2, *}$, Yujiang Yuan ${ }^{1,2}$, Shulong $\mathrm{Yu}^{1,2}$, \\ Huaming Shang ${ }^{1,2}$, and Tongwen Zhang ${ }^{1,2}$ \\ ${ }^{1}$ The Key Laboratory of Tree-ring Physical and Chemical Research of China Meteorological Administration, Institute of Desert \\ Meteorology, China Meteorological Administration \\ ${ }^{2}$ Xinjiang Laboratory of Tree-Ring Ecology, Institute of Desert Meteorology, China Meteorological Administration \\ ${ }^{3}$ College of Earth and Environmental Science, Lanzhou University, Lanzhou, China
}

Received 19 November 2012, accepted 18 June 2013

\begin{abstract}
Numerous dendro-climatic reconstructions have been developed for China, but there are still regions with limited data of this type. One region is the Qinling Mountains which is characterized by complex interactions between the mountains and climate. Presently, the subalpine region of the Qinling Mountains is covered by widespread forests and has great potential for dendroclimatological studies. Here we developed tree-ring width chronologies from two fir (Abies faxoniana) and one spruce (Picea brachytyla) sites in the Baishui River Nature Reserve, the western region of the Qinling Mountains, China. Climate response analysis reveals that radial growth of the fir site (TLD) is mainly controlled by temperature variations. The TLD chronology accounts for 32.7\% of February - June temperature variance during the period 1959 - 2006. Using a linear regression approach, we reconstructed the February - June temperature of Wen County for the past 252 years. The cool periods are identified for AD 1795 - 1800, 1812 - 1827, 1881 - 1888, 1895 - 1902, 1916 - 1929, 1967 - 1972 and 1978 - 1995. Warm conditions prevailed during AD 1783 - 1794, 1801 - 1811, 1828 - 1856, 1867 - 1880, 1889 - 1894, 1903 - 1915 and 1930 - 1966. Wavelet analysis reveals the existence of some cycles (2.0 - 3.4, 5.7, 10.0 and 19.3 years). Spatial correlation analysis shows that the temperature reconstruction captures regional climatic variations over Central and Southwest China. The moving t-test indicated an abrupt warming change of our reconstruction occurred during the past 20 years. Overall, our study indicates the feasibility of combining tree-rings and the temperature to reconstruct large-scale temperature patterns over this area.
\end{abstract}

Key words: Dendroclimatology, Baishui River Nature Reserve, Ring width, Temperature reconstruction

Citation: Wang, H., F. Chen, Y. Yuan, S. Yu, H. Shang, and T. Zhang, 2013: Temperature signals in tree-ring width chronologies of alpine treeline conifers from the Baishui River Nature Reserve, China. Terr. Atmos. Ocean. Sci., 24, 887-898, doi: 10.3319/TAO.2013.06.18.01(A)

\section{INTRODUCTION}

With their high resolution and reliability, tree rings provide one of the best sources of proxy climate data. Depending on the locations and strength of climate forcing, information concerning different climatic variables can be recovered on centennial to millennium timescales (Cook et al. 1991; Briffa et al. 1992; Lara and Villalba 1993; Bräuning 2001; Grudd 2008; Shao et al. 2010). Furthermore, large-scale climate variations have also been successfully reconstructed (Jones et al. 1998; Mann et al. 1999; Briffa 2001; Esper et al. 2002; Moberg et al. 2005; D'Arrigo et al. 2006). Trees

\footnotetext{
* Corresponding author

E-mail:feng653@163.com
}

growing close to the high altitudinal or latitudinal treeline respond to temperatures; several temperature reconstructions at high altitude have been made using tree-ring data from the Northern Hemisphere (Cook et al. 2003; Esper et al. 2003; Bräuning and Mantwill 2004; Büntgen et al. 2008; Fan et al. 2009; Wang et al. 2009; Chen et al. 2010).

Many sample sites and species in Asia are suitable for studies of dendroclimatology, including the Qinling Mountains. The Qinling Mountains are an east-west oriented $1500 \mathrm{~km}$ long mountain range in central China. It is an important geographic demarcation line and the most critical boundary for climate and vegetation distribution in central mainland China, separating southern and northern regions of China. Because of its size, high elevation and east-to-west arrangement, the 
Qinling Mountains constitute a huge physical obstacle for the movement of the synoptic regimes of China and are thus critical to the distribution of climate zones in China. Many dendrochronological studies have been carried out in the central and east Qinling Mountains and adjacent regions (Hughes et al. 1994; Shao and Wu 1994; Liu and Shao 2003; Garfin et al. 2005; Dang et al. 2007; Liu et al. 2008). However, no dendrochronological study has yet focused on climate variability in the western Qinling Mountains.

To better understand the tree growth-climate relationships in the western Qinling Mountains, the climate response of Fir (Abies faxoniana) and Spruce (Picea brachytyla) at different elevation sites from the Baishui River Nature Reserve in the western Qinling Mountains was investigated. Tree-ring widths were then assessed for their usefulness in providing stable reconstructions of climate. Finally, we then analyzed the climatic signals in tree-ring widths in the upper elevation site for the past 252 years.

\section{MATERIALS AND METHODS}

\subsection{Study Area}

The study areas are located near the Baishui River between the Min and western Qinling Mountains, southwest China (Fig. 1). There are four vegetation zones arranged with elevations varying from 700 to $3200 \mathrm{~m}$ along the southern slope of the Mountains. The fir-spruce forest extends from 2600 to $3200 \mathrm{~m}$, which is the upper elevation limit of the forest distribution, called the fir-spruce forest line or more generally, the treeline. The treeline is actually a transition zone between fir-spruce forests and alpine meadows which is composed of fascicular fir and spruce trees and trees islands. They are dominated by fir (Abies faxoniana) and spruce (Picea brachytyla) (Fig. 2). The soil types are dark brown coniferous forest soils. The study areas were chosen for the following reasons: (1) the areas are unlikely to be affected by anthropogenic activity. (2) fir-spruce treelines around the western Qinling Mountain area are typical fir-spruce treelines in Southwest China. (3) The zone is a transitional zone between a subtropical and warm temperature zone in Southwest China.

The climate of this region is strongly influenced by the Asian monsoon. At the treeline, the climate characterized by cold and windy conditions in winter, rainy and wet conditions in summer. At the meteorological station in Wen County ( $32^{\circ} 57^{\prime} \mathrm{N}, 104^{\circ} 40^{\prime} \mathrm{E}, 1014.3 \mathrm{~m}$ a.s.1.), the mean annual precipitation is about $441.5 \mathrm{~mm}$ while the mean annual temperature is $15.0^{\circ} \mathrm{C}$ (average temperatures of January and July are 3.9 and $24.9^{\circ} \mathrm{C}$ from 1959 to 2006 , respectively). July is the hottest month while July is also the wettest month

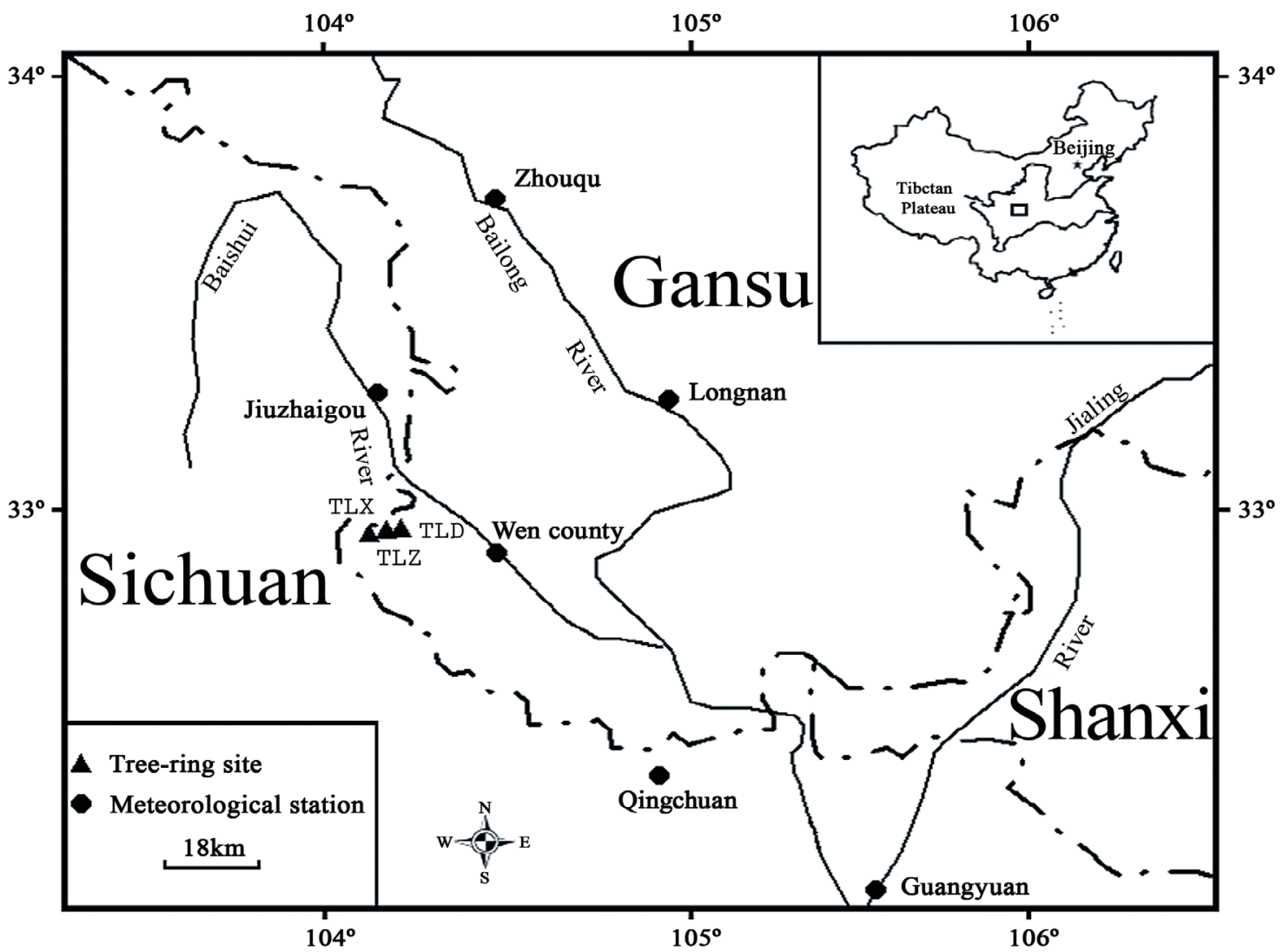

Fig. 1. Sampling sites and meteorological stations. 


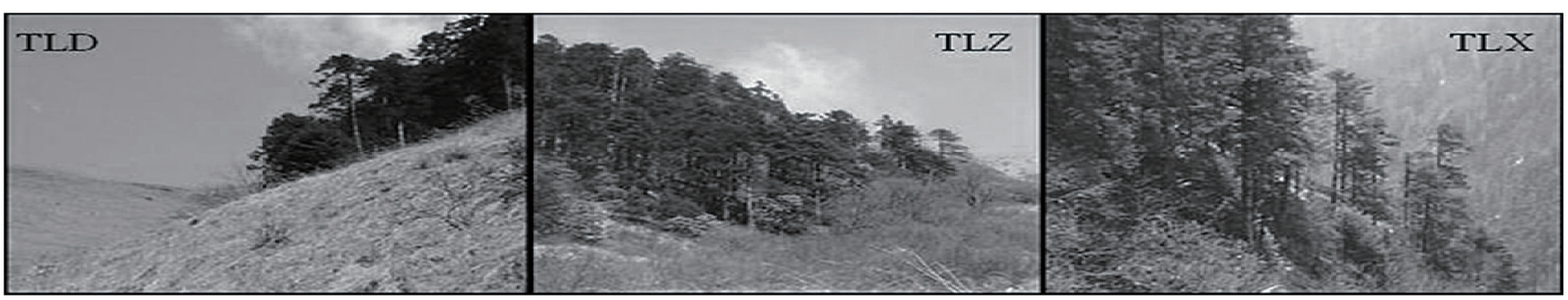

Fig. 2. The three sites in the Baishui River Nature Reserve, China.

(Fig. 3). The mean annual frost-free period is 238 days while the mean relative humidity is $60 \%$.

\subsection{Tree-Ring Sampling and Chronology Development}

Spruce (Picea brachytyla) and fir (Abies faxoniana) were sampled at three sites for the analyses performed herein. The sites are located in the Baishui River National Nature Reserve. To minimize non-climatic effects on tree growth, only trees with no injury and disease were sampled. Two cores were taken from each tree with increment borers. In all, 126 cores from 63 trees were collected. Site information, including latitude and longitude, species, slope, length of chronologies, and tree number, is listed in Table 1. Site elevations are generally around $2800 \mathrm{~m}$ or above. Coniferous species typically grow at these altitudes, and broad-leaved species at lower elevations. The slopes range from 20 to 50\%, and are generally $20-30 \%$. The mean correlations of the individual cores (with master) range between 0.471 and 0.549 .

After mounting and progressively sanding to $>400$ grit, the cores were subjected to standard dendrochronological methods (Cook and Kairiukstis 1990). After annual ring widths were measured to the nearest $0.001 \mathrm{~mm}$ using a Velmex measuring system, we used the program COFECHA (Holmes 1983) to test the accuracy of visual cross-dating and measurement of ring widths. Each individual ringwidth series was standardized with a fixed 80 year spline function in order to remove non-climatic trends due to age, size, and stand dynamics (Fritts 1976). Standardization was performed using the ARSTAN program (Cook and Kairiukstis 1990). The detrended data from individual tree cores were combined into site chronologies using a bi-weight robust mean (Cook and Kairiukstis 1990). When outliers (abnormal narrow and wide rings caused by individual factors except climate) are present, the arithmetic mean is no longer a minimum variance estimate of population mean, and may be biased (Cook and Kairiukstis 1990). The bi-weight robust mean minimizes the influence of outliers, extreme values or biases in tree-ring indices (Cook and Kairiukstis 1990). The variance in chronologies was stabilized in the chronology compilation process with the Briffa Rbar-weighted method, which uses average correlations between series in combination with sample size each year to make adjustments in the variance for changes in sample size (Osborn et al. 1997). The ARSTAN program produces three versions of standardized chronologies: Standard, Residual and Arstan (Fig. 4).

We used the expressed population signal (EPS), which represents the degree to which a particular sampling portrays a hypothetically perfect chronology (Wigley et al. 1984) as a guide in evaluating chronology reliability. The level of 0.85 for EPS is considered to indicate a satisfactory quality of a chronology.

\subsection{Methods}

The relationship between tree-ring indices and the climatic data was analyzed using program SPSS and DENDROCLIM2002 (Biondi and Waikul 2004). All statistical procedures were evaluated at a $p<0.05$ level of significance. Tree growth can be influenced by climate conditions in current and previous years (Fritts 1976). Therefore, the local climate data (Wen County) with ring width series were examined from the previous July to the current September in the response function and correlation analysis. Partial correlation analyses between radial increment and climate were also used to avoid the inter-correlation among climatic variables. In order to avoid over-fitting, the stepwise regression

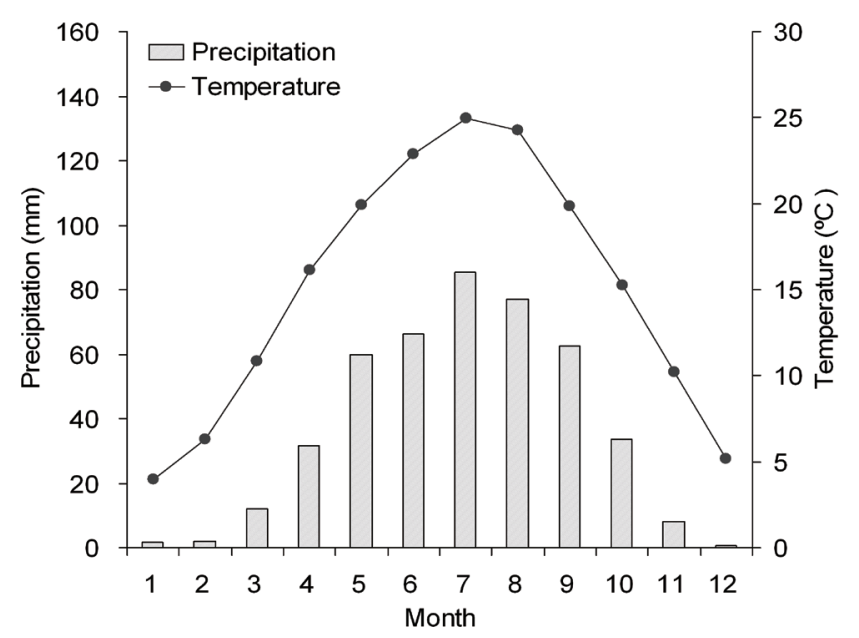

Fig. 3. Climate diagram for the meteorological station in Wen County in the western Qinling Mountains, China. 
Table 1. Information about the sampling sites in the Baishui River Nature Reserve, China.

\begin{tabular}{cccccccccc}
\hline Site & Longitude (N) & Latitude $(\mathbf{E})$ & Species & Tree number & Elevation (m) & Slope & Aspect & $\begin{array}{c}\text { Mean correlation } \\
\text { with master }\end{array}$ & Period \\
\hline TLX & $32^{\circ} 55^{\prime}$ & $104^{\circ} 14^{\prime}$ & Picea brachytyla & 21 & 2850 & $20-30^{\circ}$ & Southeast & 0.473 & $1682-2006$ \\
TLZ & $32^{\circ} 56^{\prime}$ & $104^{\circ} 18^{\prime}$ & Abies faxoniana & 18 & 2950 & $20-30^{\circ}$ & Southeast & 0.471 & $1784-2006$ \\
TLD & $32^{\circ} 56^{\prime}$ & $104^{\circ} 20^{\prime}$ & Abies faxoniana & 24 & 3150 & $20-50^{\circ}$ & Southwest & 0.549 & $1737-2006$ \\
\hline
\end{tabular}
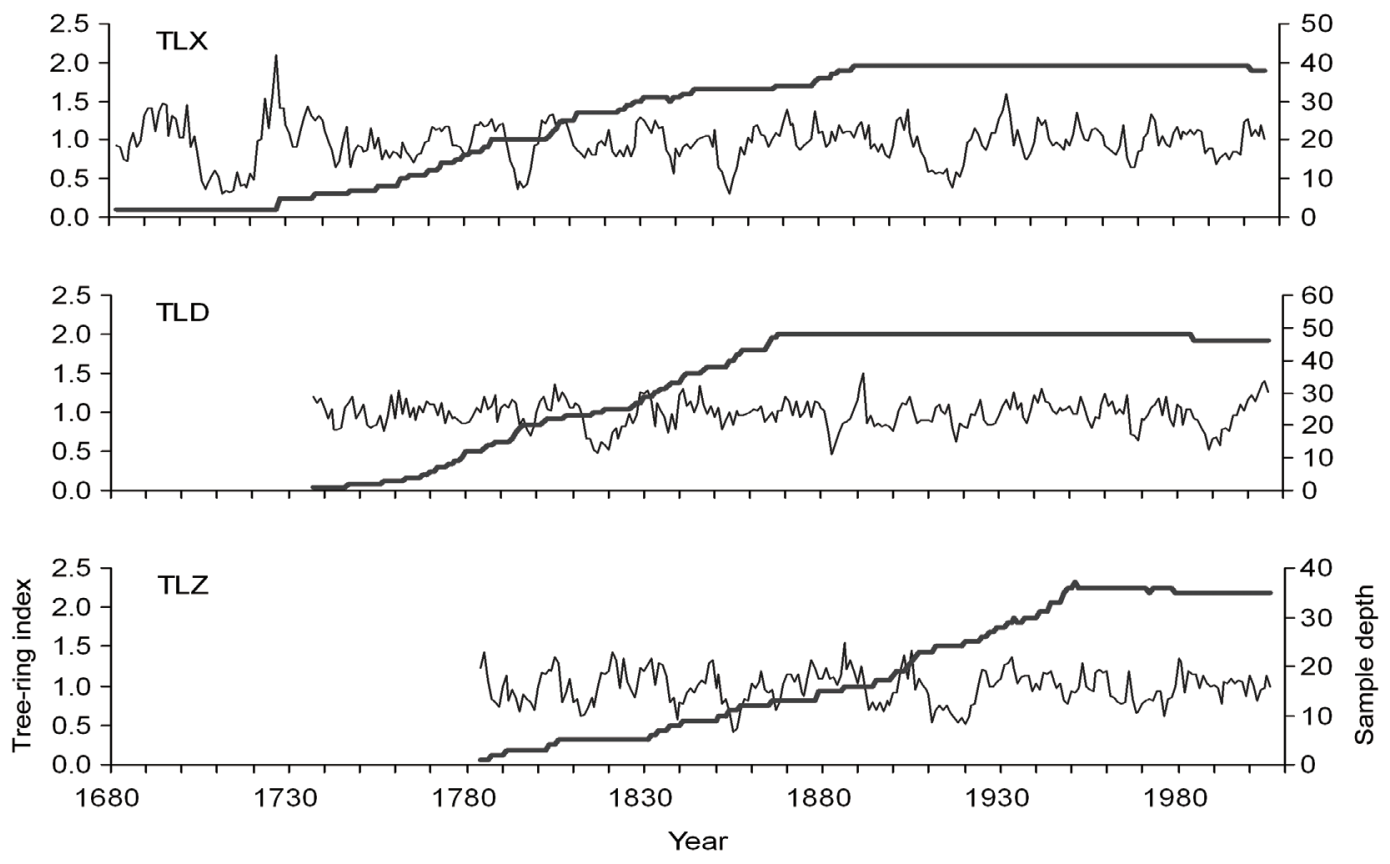

Fig. 4. Plot of the standard chronologies of the Baishui River Nature Reserve and the sample size.

analysis was used to reconstruct the climate of the western Qinling Mountains. Because the climate record is not long enough to be divided into calibration and verification sections, the leave-one-out cross-validation method was used to evaluate the goodness-of-fit of the model (Blasing et al. 1981). Statistics used to test the reliability of the reconstruction models included the reduction of error (RE), coefficient of efficiency (CE) statistics, the sign test, the Pearson's correlation coefficient and the product means test statistics (PMT) (Fritts 1976; Cook and Kairiukstis 1990).

Wavelet analysis was used to investigate periodicity of temperature reconstruction. Wavelet analysis allows the detection of significant periodic signals (waveforms) by expanding a one-dimensional time series into a two-dimensional time-frequency space. This method allowed the simultaneous representation of the dominant modes of variability (periodic signals) and the variation of those modes over time (Torrence and Compo 1998). The wavelet function used in the study was a Morlet wavelet with a wave number of six, and the wavelet power significant at the 5\% level was tested against a red noise process. The moving t- test was used to detect abrupt changes and trends within the reconstruction period (Sneyers 1992; Fraedrich et al. 1997). To demonstrate that our reconstruction represents regional temperature variations, we conducted spatial correlations between our temperature reconstruction and the gridded temperature dataset of CRUTS3.0 (Climate Research Unit, Mitchell and Jones 2005) for the period 1901 - 2006 using the KNMI climate explorer (http://climexp.knmi.nl; Trouet and Oldenborgh 2013).

\section{RESULTS}

\subsection{The Characteristics of Tree-Ring Width Chronolo- gies}

Table 2 shows the statistics of the chronologies produced by the standardization program ARSTAN based on tree-ring widths from the three sites. The strength of signals expressed by the tree-ring indices increased with the increase in the number of sample replications. Consequently, the chronology intervals used in the analysis were 1728 - 2006 for the TLX chronology, 1768 - 2006 for the TLD chronology, 
Table 2. Chronology statistics for the standardized tree-ring width chronologies used in the study.

\begin{tabular}{ccccccc}
\hline Site & Mean sensitivity & $\begin{array}{c}\text { Standard } \\
\text { deviation }\end{array}$ & $\begin{array}{c}\text { Auto-correlation } \\
\text { order 1 }\end{array}$ & $\begin{array}{c}\text { Signal-to-noise } \\
\text { ratio }\end{array}$ & $\begin{array}{c}\text { Variance in first } \\
\text { eigenvector }\end{array}$ & $\begin{array}{c}\text { Expressed population } \\
\text { signal }\end{array}$ \\
\hline TLX & 0.144 & 0.260 & 0.774 & 21.326 & 0.387 & 0.955 \\
TLZ & 0.144 & 0.212 & 0.652 & 4.821 & 0.336 & 0.828 \\
TLD & 0.129 & 0.176 & 0.602 & 20.737 & 0.336 & 0.954 \\
\hline
\end{tabular}

and 1806 - 2006 for the TLZ chronology which contained at least five sample replications for each year. In general, higher signal-to-noise ratios (SNR) and expressed population signals (EPS) indicating that the radial growth of different trees was responding to common factors (Cook and Kairiukstis 1990). The TLX and TLD chronology had higher a EPS and SNR compared with the TLZ chronology. The first-order autocorrelation (AC1) for the three chronologies ranged from 0.602 to 0.774 which showed that the conditions that cause a ring to be narrow (or wide) in one year tend to carry over their effect on the growth of the following year. Variance in first eigenvector (VFE) accounted for 33.6 - 38.7\% of the variance in the site chronologies. The mean sensitivity (MS) of three chronologies was rather small; nevertheless; it was enough to obtain accurate results with response function methods (Rolland 1993). The three chronologies of the western Qinling Mountains showed a common signal though with an altitude difference of $300 \mathrm{~m}$ (Table 3).

\subsection{Climate Response Analysis}

In the view of the coefficients of all the response func- tions (Table 4), 10 significant coefficients occurred in the growth season (March - September) compared with 8 in the other 8 months. Correlations between tree-ring widths and precipitation are found to be not significant (with the exception of November of the previous year and June of the current year). This indicates that ring widths are better at reflecting temperature than precipitation conditions. Fifteen significant coefficients in monthly mean temperature and monthly maximum temperature are more than 1 significant coefficient in monthly minimum temperature. Twelve significant coefficients between the TLD chronology and

Table 3. Cross-correlations for tree-ring indices during the common periods

\begin{tabular}{cccc}
\hline & TLX & TLD & TLZ \\
\hline TLX & & & \\
TLD & $0.484^{*}$ & & \\
TLZ & $0.684^{*}$ & $0.269^{*}$ & \\
\hline
\end{tabular}

Note: *Significant at the $1 \%$ level.

Table 4. Summary of the significant response function coefficients $(p<0.05)$.

\begin{tabular}{|c|c|c|c|c|c|c|c|c|c|c|c|c|c|c|c|c|}
\hline Month & & $\mathbf{J}$ & $\mathbf{A}$ & $\mathbf{S}$ & $\mathbf{O}$ & $\mathbf{N}$ & $\mathbf{D}$ & $\mathbf{J}$ & $\mathbf{F}$ & M & $\mathbf{A}$ & $\mathbf{M}$ & $\mathbf{J}$ & $\mathbf{J}$ & $\mathbf{A}$ & $\mathbf{S}$ \\
\hline \multirow{3}{*}{ Monthly total precipitation } & TLX & & & & & & & & & & & & & & & \\
\hline & TLZ & & & & & - & & & & & & & & & & \\
\hline & TLD & & & & & & & & & & & & - & & & \\
\hline \multirow{3}{*}{ Monthly mean temperature } & TLX & & & & & & & & + & & & & & & & \\
\hline & TLZ & & & & & + & & & & & & & & & & \\
\hline & TLD & & & + & + & & & + & & + & + & + & & + & & \\
\hline \multirow{3}{*}{ Monthly maximum temperature } & TLX & & & & & & & & & & - & & & & & \\
\hline & TLZ & & & & & + & & & & & & & & & & \\
\hline & TLD & + & & & & & & & & + & & & + & + & & \\
\hline \multirow{3}{*}{ Monthly minimum temperature } & TLX & & & & & & & & & & & & & & & \\
\hline & TLZ & & & & & & & & & & & & & & & \\
\hline & TLD & & & & & & & & & & & & & & + & \\
\hline
\end{tabular}

Note: + means positive correlation, - means negative correlation. 
temperature are more than 4 significant coefficients in other two chronologies. Correlations between TLD chronology and mean temperatures reveal significant positive $(p<0.01)$ responses to monthly March, April, May and July.

To investigate the climate-tree-ring relationship in more detail, we screened the tree-ring chronologies in a correlation analysis with the seasonal combinations of temperatures and precipitation from the previous July to current September. The upper-elevation chronology (TLD) shows a significant positive response to the temperature of the premonsoon season. The highest correlation is $0.572(p<0.01)$ between tree-ring width and the monthly mean temperature (February - June).

\subsection{The temperature (February - June) reconstruction}

Based on the above climate response analysis results, mean February - June temperature is the most appropriate predictor for reconstruction. A regression equation of the mean February - June temperature of Wen County on the tree-ring width chronology (TLD) for the calibration period 1959 - 2006 was developed.

The resulting statistics of leave-one-out cross validation are shown in Table 5. Both the RE and CE are strongly positive for both of the calibration periods, indicating considerable validity in the reconstruction model. The results of the sign test which describes how well the predicted value tracks the direction of actual data exceed the $95 \%$ confidence level. The product means test is found to be significant at the 0.001 level. These results indicate that the model used here passed the critical tests for verification and was optimized by achieving the greatest predictive capability for the fewest independent variables. Highest correlation of 0.784 was revealed after decadal-scale band-pass filtering (10 years), indicating that the strong climate signal is retained at low- frequency band. Temperature data for the full 1959 - 2006 period was then used to calibrate the final reconstruction (Fig. 5). The final temperature reconstruction explains $32.7 \%$ of the variance and extends from AD $1755-2006$.

The reconstructed and 10-year low-pass filtered February - June temperature in Wen County is presented in Fig. 6. The reconstruction contains considerable low-frequency climate variations during the past 252 years. The long-term mean of the temperature reconstruction over the period $\mathrm{AD}$ $1755-2006$ is estimated at $15.24^{\circ} \mathrm{C}$. According to the reconstruction, cool periods with below-average temperature occurred in AD 1795 - 1800, 1812 - 1827, 1881 - 1888, 1895 - 1902, 1916 - 1929, $1967-1972$ and $1978-1995$. Among them, interval AD 1812 - 1827 witnessed the most severe and extended cool episode in the western Qinling Mountains over the past 252 years. The warm periods with the temperature higher than mean occurred in AD 1783 1794, 1801 - 1811, 1828 - 1856, 1867 - 1880, 1889 - 1894, $1903-1915,1930-1966$. There are some stable periods among cool and warm periods. $1817\left(14.28^{\circ} \mathrm{C}\right)$ and 1892 $\left(16.22^{\circ} \mathrm{C}\right)$ are reconstructed as the most extreme years.

The wavelet analysis over the full range of our reconstruction revealed some low-and high-frequency cycles (Fig. 7). Low-frequency peaks were found at 19.3 years (at 95\% level) and 10.0 years (95\%). The decadal cycles suggest the influence of solar forcing on the climate there (Shao and Fan 1999; Yu et al. 2012). Other significant peaks were found at 5.7 year (95\%) and $2.0-3.4$ year (95\%). Most of these interannual cycles fall within the range of the El NiñoSouthern Oscillation (ENSO) variability (Allan et al. 1996), suggesting strong teleconnections between ENSO and the climate variability in southwestern China (Li 1989; Fan et al. 2008a).The application of a moving t-test showed that there were six abrupt points in the temperature reconstruction, included 1812, 1827, 1849, 1880, 1986 and 1995.

Table 5. Leave-one-out cross-validation statistics for reconstruction of February-June temperature in Wen County based on tree-ring index of the TLD chronology.

\begin{tabular}{cccccccc}
\hline $\boldsymbol{r}$ & $\boldsymbol{r}^{\mathbf{2}}$ & $\boldsymbol{F}$ & Signal-test & RE & CE & PMT & Durbin-Watson \\
\hline 0.572 & 0.327 & 22.30 & $16^{+} / 32$ & 0.270 & 0.255 & 3.001 & 1.767 \\
\hline
\end{tabular}

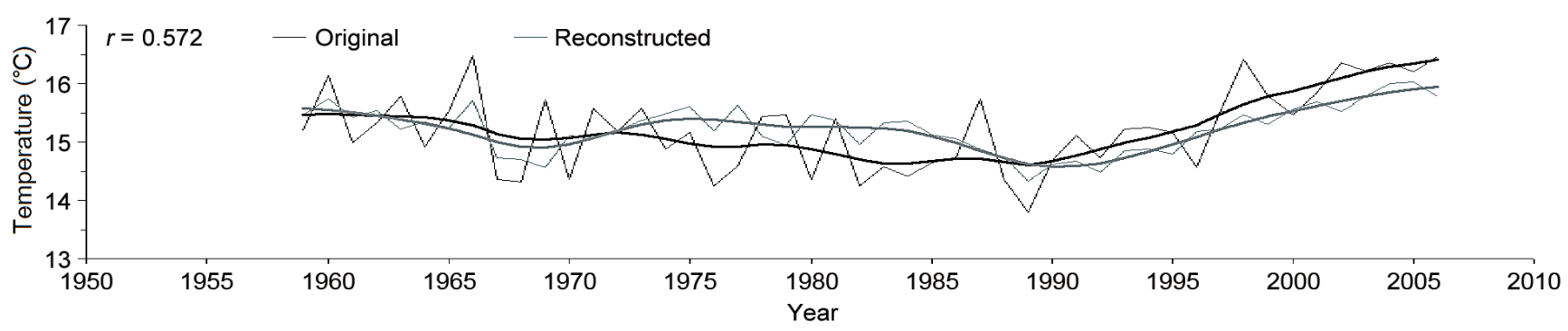

Fig. 5. Comparison of the actual and reconstructed February-June temperature. The bold curves are 10-year low-pass filters $(r=0.784)$. 


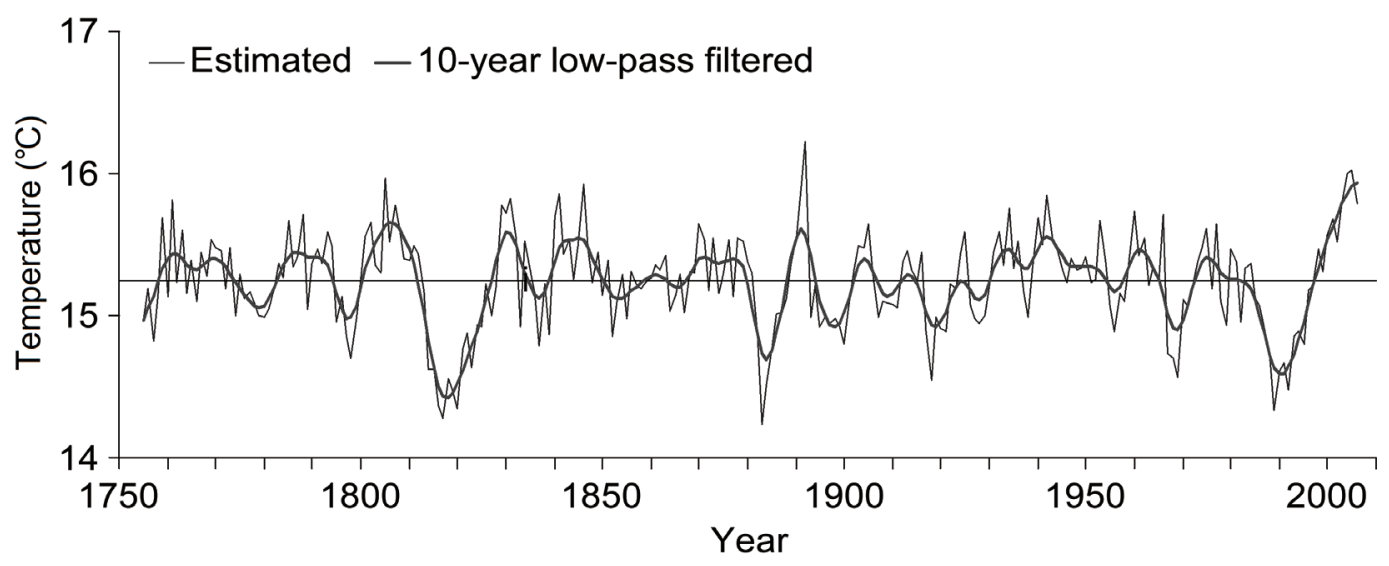

Fig. 6. Reconstructed February-June temperature of Wen County with 10-year smoothing (thick line).

(a) Wavelet Power Spectrum

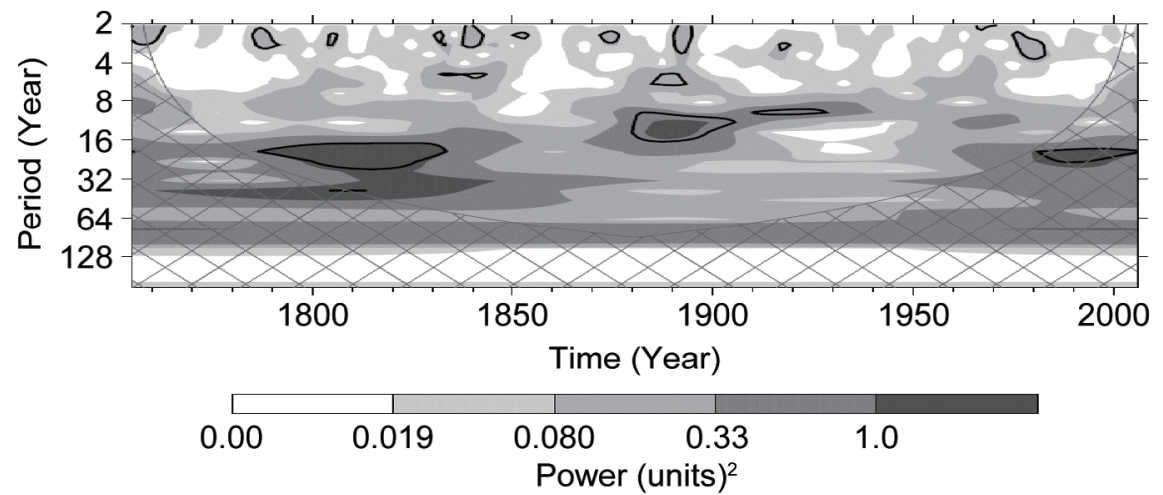

(b) Global Wavelet

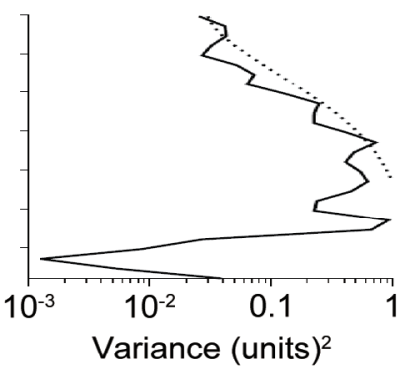

Fig. 7. (a) The wavelet power spectrum. The grey contour intervals represent $75,50,25$ and $5 \%$ of the wavelet power, respectively. Black contours are the $5 \%$ significant level, using a red-noise (autoregressive lag 1) background spectrum. (b) The global wavelet power spectrum.

Our reconstruction is associated with a temperature field north of approximately $25-38^{\circ}$ latitude with a large east-west extension. The highest correlations occurred in the Sichuan-Shanxi-Gansu border region where the ' 5.12 ' Wenchuan earthquake happened, especially in south Gansu (Fig. 8). The results confirm that our temperature reconstruction captures broad-scale regional climatic variations.

\section{DISCUSSION}

In general, tree-ring width data at the upper-elevation sites studied were highly correlated with temperature, rather than with precipitation. Our study also showed that the correlations between tree-ring widths and growth season temperature were higher at the upper-elevation site than lower-elevation site. For the upper-elevation site, higher temperatures could result in melted snow cover and increased soil moisture, leading to an advanced onset of the growing season. The temperature starts rising in March; April and May is a comparatively warm period. The climate of this region is strongly influenced by the Asian monsoon. The windward slopes of the study areas can receive 250 - $300 \mathrm{~mm}$ rainfall in the monsoon season. Although June and July are hot, moisture stress is no longer a problem because of the beginning of monsoonal rains. Therefore, precipitation is not the main factor limiting the radial growth of spure-fir trees in the western Qinling Mountains. Such a higher temperature and plentiful rainfall can lead to high radial growth at the upper-elevation site (TLD).

Evidence of warm periods in the 1780 s and in the 1800s were reported from northeast Tibet (Gou et al. 2007), the central Hengduan Mountains (Fan et al. 2008b), the western Himalaya (Hughes 2001; Yadav et al. 2004) and Nepal (Cook et al. 2003). The warm period from 1828 to 1856 has also been detected by Wu et al. (1988) and Fan et al. (2008b) in the Hengduan Mountains. The warm 1850s are consistent with the warm winters in the eastern Tibetan Plateau (Bräuning 2006) and warm summers in Kashmir in the western Himalayas (Hughes 2001). The warm period from 1930 to 1966 has also been documented by Fan et al. 
(2008b) in the Hengduan Mountains.

As shown in Fig. 8, some significant areas of correlation were found on the Indian subcontinent suggesting that our study region is affected by the regimes of the south Asian monsoon. To further investigate the common large-scale temperature signals of the south Asian monsoon region, we compare the new record with the February - June temperature reconstruction of Kathmandu (Nepal). The correlation coefficient between our temperature reconstruction and Kathmandu reconstruction is 0.261 ( $p<0.01)$, and increasing $(0.402, p<0.01)$ coherence after a filtered 10-year low-pass (Fig. 9). The two temperature reconstructions indicate the occurrence of unusually cold temperatures in 1812 - 1827. The tree growth in Europe and
North America was greatly limited by the unusually cold temperatures in 1815 and 1816 (Filion et al. 1986; Lamb 1995; Briffa et al. 1992; Davi et al. 2002; Davi et al. 2003; Bräuning and Mantwill 2004; Büntgen et al. 2008; Fan et al. 2009; Wang et al. 2009). This may be linked with the volcanic eruption of Tambora (Indonesia) in April 1815. This eruption probably influenced the atmospheric circulation patterns of the monsoonal currents, and has been linked with the strong depression in tree growth in the south Asian monsoon region (Fan et al. 2008b). Wavelet analysis of the reconstructed temperature series suggested the existence of a 19-year climatic cycle during the period 1780 - 1830, which indicated that the beginning of cooling may be earlier than 1815 . It indicates (a)

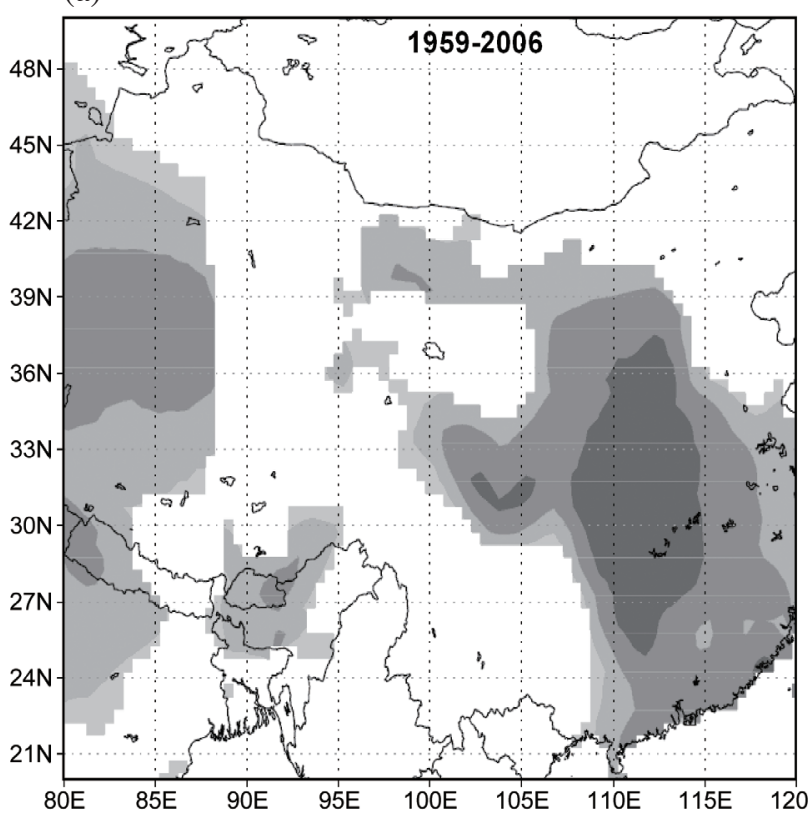

(b)

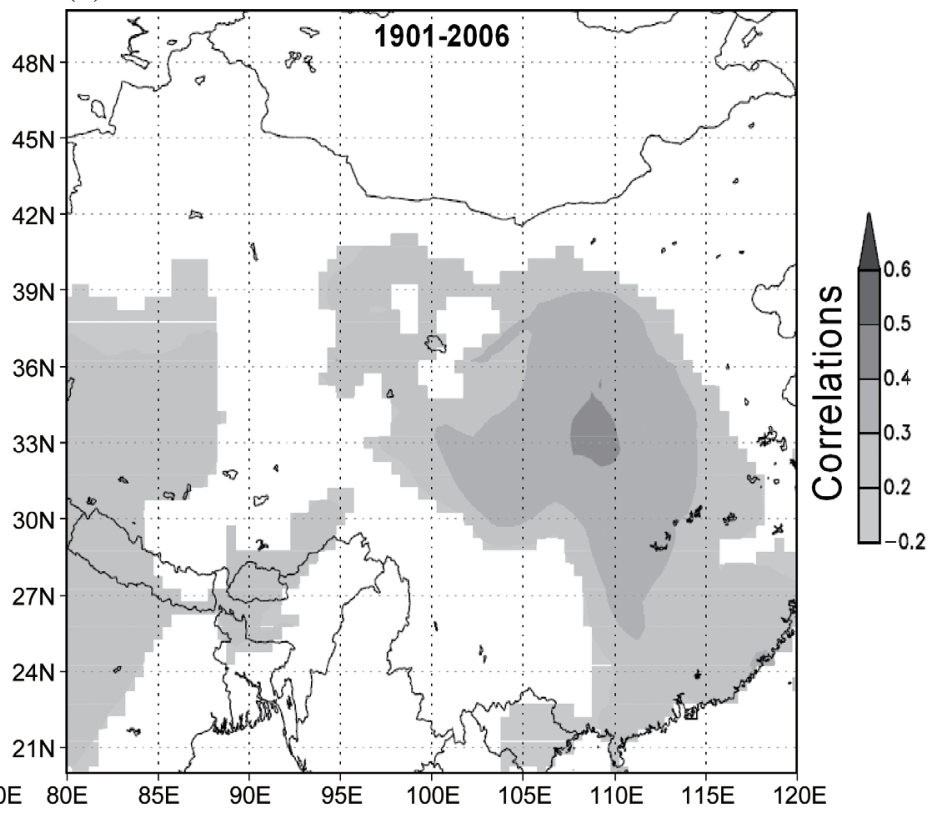

Fig. 8. Spatial correlation fields of the February - June temperature reconstruction for Wen County with the gridded dataset of February - June temperature for the period $1901-2006$.

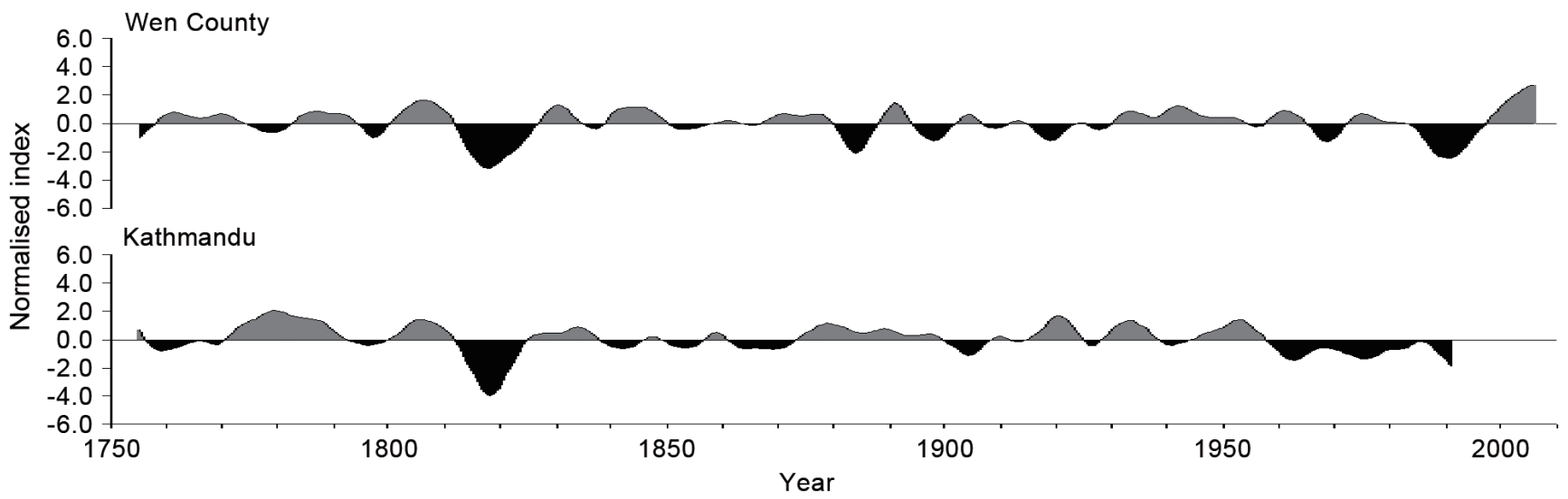

Fig. 9. Graphical comparison between the February - June temperature reconstruction in Wen County and the temperature reconstruction of Kathmandu (Nepal) after 10-year low-pass filtered. 
this period is not only affected by the tropical eruptions, but also along with cooler conditions due to low solar activity in the Dalton minimum. Cold periods during the 1881 - 1888 and 1895 - 1902 found in the present study are consistent with low temperatures in neighboring regions (Fan et al. 2010). However, temperature changes in our study area diverge considerably from that reported for Nepal during the two cold periods (Cook et al. 2003). The radial growth of the TLD site seemed to respond better to volcanic eruptions (Simkin and Siebert 1994). Taken together, the volcanic eruptions may have affected a large area in southwest China.

Warming in the $20^{\text {th }}$ century has been observed in treering reconstructions of temperature from widespread regions of Eurasia (Jacoby et al. 1996; Briffa et al. 2002; Gou et al. 2007; Büntgen et al. 2008; Chen et al. 2010). Based on instrument data and other proxies, Wang et al. (2004) showed that temperature anomalies during the period 1920 - 1950 are noticeably positive over China throughout the last century. Warm conditions around 1950, and the cool period around 1970 were also reported in west Sichuan (Shao and Fan 1999), the central Hengduan Mountains (Fan et al. 2008b) and Tibet (Bräuning and Mantwill 2004). The pronounced negative summer temperature trends around 1970. The cold period of the 1970s is noted not only in adjusted Nepal and China areas (Shao and Fan 1999; Bräuning and Mantwill 2004; Fan et al. 2008b), but also in other areas of the northern hemisphere (Briffa et al. 2001; Esper et al. 2002; Büntgen et al.2008). This is probably the consequence of enhanced rainfall in Wen county and thus of increasing monsoon intensity (Bräuning and Mantwill 2004). The moving t-test indicated that the strongest abrupt warming change of our reconstruction occurred in 1995. Temperature reconstructions based on ring widths and densities indicated a warming trend occurred in 1990s in southwestern China and Tibetan Plateau, which coincided with the $20^{\text {th }}$ century warming (Shao and Fan 1999; Bräuning and Mantwill 2004; Song et al. 2007; Fan et al. 2008b; Wu et al. 2008; Fan et al. 2009; Duan et al. 2010). The tree-ring data in Mongolia and Siberia revealed a similar abrupt rise of temperatures in the late $20^{\text {th }}$ century (Jacoby et al. 1996; Briffa et al. 2002). Giant pandas in the Baishui River Nature Reserve may be shifting their habitats northward because of the combined impact of this warming trend (Wu and Lv 2009; Tuanmu et al. 2013). The February - June temperature reconstruction of Kathmandu ended at AD 1991, so it did not reflect the extent of recent warming (Cook et al. 2003).

\section{CONCLUSION}

We compared tree-ring width chronology characteristics and climate-growth responses of high-elevation conifers along an elevation gradient in the western Qinling Mountains. As indicated by climate response analysis, the temperatures of a pre-monsoon season (February - June) have a strong influence on ring width at the upper elevation site. The mean February - June temperature for the past 252 years was reconstructed for Wen County in the western Qinling Mountains. The reconstruction explained $32.7 \%$ of the variance of the instrumental temperature over the common period 1959 - 2006. According to the reconstruction, cool periods with below-average temperature occurred in AD 1795 - 1800, 1812 - 1827, 1881 - 1888, 1895 - 1902, 1916 - 1929, 1967 - 1972 and 1978 - 1995. The warm periods with the temperatures higher than the mean occurred in AD 1783 - 1794, 1801 - 1811, 1828 - 1856, 1867 - 1880, 1889 - 1894, 1903 - 1915, 1930 - 1966. The temperature reconstruction in Wen County is representative of a large-scale regional temperature variability extending to areas to its south and east and corresponds well with a temperature reconstruction of the pre-monsoon season from Kathmandu, Nepal. As indicated by the two reconstructions, the cold years from 1812 - 1827 is the most severe and long-lasting since AD 1752. During the past 20 years, the strongest increase of temperatures during the last 252 years can be observed and are almost at the same level than during the warmest period observed. This temperature maximum will soon be topped, if the warming trend observed for the last 20 years will continue.

Acknowledgments This work was supported by the Basic Research Operating Expenses of the Central-level Non-profit Research Institutes (IDM201105), Meteorology Public Welfare Industry Research Special Project (GYHY201106013), NSFC Project (No. 40975056 and No. 41071072), China Desert Meteorological Science Research Foundation (SQJ2010011), the Foundation of Xinjiang Laboratory of Tree-ring Ecology (XJYS0911-2009-01). We thank the reviewers whose comments greatly benefitted this manuscript.

\section{REFERENCES}

Allan, R. J., J. Lindesay, and D. E. Parker, 1996: El Niño: Southern Oscillation \& Climatic Variability, CSIRO Publishing, Collingwood, 405 pp.

Biondi, F. and K. Waikul, 2004: DENDROCLIM2002: A $\mathrm{C}++$ program for statistical calibration of climate signals in tree-ring chronologies. Comput. Geosci., 30, 303-311, doi: 10.1016/j.cageo.2003.11.004. [Link]

Blasing, T. J., D. N. Duvick, and D. C. West, 1981: Dendroclimatic calibration and verification using regionally averaged and single station precipitation data. Treering Bull., 41, 37-43.

Bräuning, A., 2001: Combined view of various tree ring parameters from different forest habitats in Tibet for the reconstruction of seasonal aspects of Asian monsoon variability. Palaeobotanist, 50, 1-12.

Bräuning, A., 2006: Tree-ring evidence of 'Little Ice Age' glacier advances in southern Tibet. Holocene, 16, 369380 . 
Bräuning, A. and B. Mantwill, 2004: Summer temperature and summer monsoon history on the Tibetan Plateau during the last 400 years recorded by tree rings. Geophys. Res. Lett., 31, doi: 10.1029/2004GL020793. [Link]

Briffa, K. R., P. D. Jones, and F. H. Schweingruber, 1992: Tree-ring density reconstructions of summer temperature patterns across western North America since 1600. J. Climate, 5, 735-754, doi: 10.1175/1520-0442(1992) 005<0735:TRDROS>2.0.CO; . [Link]

Briffa, K. R., T. J. Osborn, F. H. Schweingruber, I. C. Harris, P. D. Jones, S. G. Shiyatov, and E. A. Vaganov, 2001: Low-frequency temperature variations from a northern tree ring density network. J. Geophys. Res., 106, 2929-2941, doi: 10.1029/2000JD900617. [Link]

Briffa, K. R., P. D. Jones, F. H. Schweingruber, S. G. Shiyatov, and E. R. Cook, 2002: Unusual twentiethcentury summer warmth in a 1,000-year temperature record from Siberia. Nature, 376, 156-159, doi: 10.1038/376156a0. [Link]

Büntgen, U., D. Frank, H. Grudd, and J. Esper, 2008: Longterm summer temperature variations in the Pyrenees. Climate Dyn., 31, 615-631, doi: 10.1007/s00382-0080390-x. [Link]

Chen, F., Y. Yuan, W. Wei, S. Yu, Y. Li, R. Zhang, T. Zhang, and H. Shang, 2010: Chronology development and climate response analysis of Schrenk spruce $(P i$ cea Schrenkiana) tree-ring parameters in the Urumqi river basin, China. Geochronometria, 36, 17-22, doi: 10.2478/v 10003-010-0014-4. [Link]

Cook, E., T. Bird, M. Peterson, M. Barbetti, B. Buckley, R. D'Arrigo, R. Francey, and P. Tans, 1991: Climatic Change in Tasmania Inferred from a 1089-Year TreeRing Chronology of Huon Pine. Science, 253, 12661268, doi: 10.1126/science.253.5025.1266. [Link]

Cook, E. R. and L. A. Kairiukstis, 1990: Methods of Dendrochronology: Applications in the Environmental Sciences, Kluwer Academic Publishers, New York, $394 \mathrm{pp}$.

Cook, E. R., P. J. Krusic, and P. D. Jones, 2003: Dendroclimatic Signals in Long Tree-Ring Chronologies from the Himalayas of Nepal. Int. J. Climatol., 23, 707-732, doi: 10.1002/joc.911. [Link]

Dang, H., M. Jiang, Q. Zhang, and Y. Zhang, 2007: Growth responses of subalpine fir (Abies fargesii) to climate variability in the Qinling Mountain, China. For. Ecol. Manage., 240, 143-150, doi: 10.1016/j. foreco.2006.12.021. [Link]

D'Arrigo, R., R. Wilson, and G. Jacoby, 2006: On the longterm context for late twentieth century warming. J.Geophys. Res., 111, D03103, doi: 10.1029/2005JD006352. [Link]

Davi, N., R. D'Arrigo, G. Jacoby, B. Buckley, and O. Kobayashi, 2002: Warm-season annual to decadal temperature variability for Hokkaido, Japan, inferred from maximum latewood density (AD 1557-1990) and ring width data(AD 1532-1990). Clim. Change, 52,201-217, doi: 10.1023/A:1013085624162. [Link]

Davi, N. K., G. C. Jacoby, and G. C. Wiles, 2003: Boreal temperature variability inferred from maximum latewood density and tree-ring width data, Wrangell Mountain region, Alaska. Quaternary Res., 60, 252262, doi: 10.1016/j.yqres.2003.07.002. [Link]

Duan, J. P., L. Wang, L. Li, and K. L. Chen, 2010: Temperature variability since A.D. 1837 inferred from tree-ring maximum density of Abies fabri on Gongga Mountain, China. Chinese Sci. Bull., 55, 3015-3022, doi: 10.1007/ s11434-010-3182-8. [Link]

Esper, J., E. R. Cook, and F. H. Schweingruber, 2002: Lowfrequency signals in long tree-ring chronologies for reconstructing past temperature variability. Science, 295, 2250-2253, doi: 10.1126/science.1066208. [Link]

Esper, J., S. G. Shiyatov, V. S. Mazepa, R. J. S. Wilson, D. A. Graybill, and G. Funkhouser, 2003: Temperaturesensitive Tien Shan tree ring chronologies show multicentennial growth trends. Climate Dyn., 21, 699-706, doi: 10.1007/s00382-003-0356-y. [Link]

Fan, Z. X., A. Bräuning, and K. F. Cao, 2008a: Tree-ring based drought reconstruction in the central Hengduan Mountains region (China) since A.D. 1655. Int. J. Climatol., 28, 1879-1887, doi: 10.1002/joc.1689. [Link]

Fan, Z. X., A. Bräuning, and K. F. Cao, 2008b: Annual temperature reconstruction in the central Hengduan Mountains, China, as deduced from tree rings. Dendrochronologia, 26, 97-107, doi: 10.1016/j.dendro.2008.01.003. [Link]

Fan, Z. X., A. Bräuning, B. Yang, and K. F. Cao, 2009: Tree ring density-based summer temperature reconstruction for the central Hengduan Mountains in southern China. Global Planet. Change, 65, 1-11, doi: 10.1016/j.gloplacha.2008.10.001. [Link]

Fan, Z. X., A. Bräuning, Q. H. Tian, B. Yang, and K. F. Cao, 2010: Tree ring recorded May-August temperature variations since A.D. 1585 in the Gaoligong Mountains, southeastern Tibetan Plateau. Palaeogeogr. Palaeoclimatol. Palaeoecol., 296, 94-102, doi: 10.1016/j. palaeo.2010.06.017. [Link]

Filion, L., S. Payette, L. Gauthier, and Y. Boutin, 1986: Light rings in subarctic conifers as a dendrochronological tool. Quaternary Res., 26, 272-279, doi: 10.1016/0033-5894(86)90111-0. [Link]

Fraedrich, K., J. Jiang, F. W. Gerstengarbe, and P.C. Werner, 1997: Multiscale detection of abrupt climate changes: Application to River Nile flood levels. Int. J. Climatol., 17,1301-1315, doi: 10.1002/(SICI)1097-0088(199710) 17:12<1301::AID-JOC196>3 .0.CO;2-W. [Link]

Fritts, H. C., 1976: Tree-Rings and Climate, Academic Press, New York, 567 pp.

Garfin, G. M., M.K. Hughes, Y.Liu, J.M. Burns, R. Touchan, 
S. W. Leavitt, and A. Zhisheng, 2005: Exploratory temperature and precipitation reconstructions from the Qinling Mountains, North-Central China. Tree-Ring Res., 61, 59-72, doi: 10.3959/1536-1098-61.2.59. [Link]

Gou, X., F. Chen, G. Jacoby, E. Cook, M. Yang, J. Peng, and Y. Zhang, 2007: Rapid tree growth with respect to the last 400 years in response to climate warming, northeastern Tibetan Plateau. Int. J. Climatol., 27, 1497-1503, doi: 10.1002/joc.1480. [Link]

Grudd, H., 2008: Torneträsk tree-ring width and density AD 500-2004: A test of climatic sensitivity and a new 1500-year reconstruction of north Fennoscandian summers. Climate Dyn., 31, 843-857, doi: 10.1007/s00382007-0358-2. [Link]

Holmes, R. L., 1983: Computer-assisted quality control in tree-ring dating and measurement. Tree-Ring Bull., 43, 69-95.

Hughes, M. K., 2001: An improved reconstruction of summer temperature at Srinagar, Kashmir since 1660 AD, based on tree-ring width and maximum latewood density of Abies pindrow [Royle] Spach. Palaeobotanist, 50, 13-19.

Hughes, M. K., X. Wu, X. Shao, and G. M. Garfin, 1994: A preliminary reconstruction of rainfall in NorthCentral China since A.D. 1600 from tree-ring density and width. Quaternary Res., 42, 88-99, doi: 10.1006/ qres.1994.1056. [Link]

Jacoby, G. C., R. D. D'Arrigo, and T. Davaajamts, 1996: Mongolian tree rings and 20th-century warming. Science, 273,771-773, doi: 10.1126/science.273.5276.771. [Link]

Jones, P. D., K. R. Briffa, T. P. Barnett, and S. F. B. Tett, 1998: High-resolution palaeoclimatic records for the last millennium: Interpretation, integration and comparison with general circulation model control-run temperatures. Holocene, 8, 455-471, doi: 10.1191/ 095968398667194956. [Link]

Lamb, H. H., 1995: Climate, History and the Modern World, Routledge, London, 464 pp.

Lara, A. and R. Villalba, 1993: A 3620-year temperature record from Fitzroya cupressoides tree rings in southern South America. Science, 260, 1104-1106, doi: 10.1126/ science.260.5111.1104. [Link]

Li, C., 1989: El Niño and warm winter over Eastern China. Chin. Sci. Bull., 34, 283-286. (in Chinese)

Liu, H. and X. Shao, 2003: Reconstruction of early-spring temperature of Qinling Mountains using tree-ring chronologies. Acta Geograph. Sin., 58, 879-884. (in Chinese)

Liu, Y., H. W. Linderholm, H. Song, Q. Cai, Q. Tian, J. Sun, D. Chen, E. Simelton, K. Seftigen, H. Tian, R. Wang, G. Bao, and Z. An, 2008: Temperature variations recorded in Pinus tabulaeformis tree rings from the southern and northern slopes of the central Qinling
Mountains, central China. Boreas, 38, 285-291, doi: 10.1111/j.1502-3885.2008.00065.x. [Link]

Mann, M.E., R. S. Bradley, and M. K. Hughes, 1999: Northern Hemisphere temperatures during the past millennium: Inferences, uncertainties, and limitations. Geophys. Res. Lett., 26, 759-762, doi: 10.1029/1999GL900070. [Link]

Mitchell, T. D. and P. D. Jones, 2005: An improved method of constructing a database of monthly climate observations and associated high-resolution grids. Int. J. Climatol., 25, 693-712, doi: 10.1002/joc.1181. [Link]

Moberg, A., D. M. Sonechkin, K. Holmgren, N. M. Datsenko, and W. Karlén, 2005: Highly variable Northern Hemisphere temperatures reconstructed from low- and high-resolution proxy data. Nature, $\mathbf{4 3 3}, 613-617$, doi: 10.1038/nature03265. [Link]

Osborn, T. J., K. R. Briffa, and P. D. Jones, 1997: Adjusting variance for sample-size in tree-ring chronologies and other regional-mean time-series. Dendrochronologia, 15, 89-99.

Rolland, C., 1993: Tree-ring and climate relationships for Abies alba in the internal Alps. Tree-Ring Bull., 53, $1-11$.

Shao, X. and X. Wu, 1994: Tree-ring chronologies for $\mathrm{Pi}$ nus ArmandiiFranch from Huashan, China. Acta Geograph. Sin., 49, 174-181. (in Chinese)

Shao, X. and J. Fan, 1999: Past climate on west Sichuan plateau as reconstructed from ring-widths of dragon spruce. Quaternary Sci., 19, 81-89. (in Chinese)

Shao, X., Y. Xu, Z.-Y. Yin, E. Liang, H. Zhu, and S. Wang, 2010: Climatic implications of a 3585-year tree-ring width chronology from the northeastern Qinghai-Tibetan Plateau. Quaternary Sci. Rev., 29, 2111-2122, doi: 10.1016/j.quascirev.2010.05.005. [Link]

Simkin, T. and L. Siebert, 1994: Volcanoes of the World: A Regional Directory, Gazetteer, and Chronology of Volcanism During the Last 10,000 Years, Geoscience Press, Tuscon, $349 \mathrm{pp}$.

Sneyers, R., 1992: On the use of statistical analysis for the objective determination of climatic change. Meteorol. Z., 1, 247-256.

Song, H., Y. Liu, W. Ni, Q. Cai, J. Sun, W. Ge, and W. Xiao, 2007: Winter mean lowest temperature derived from tree-ring width in Jiuzhaigou Region, China since 1750A.D.. Quaternary Sci., 27, 486-491. (in Chinese)

Torrence, C. and G. P. Compo, 1998: A practical guide to wavelet analysis. Bull. Amer. Meteorol. Soc., 79, 6178, doi: 10.1175/1520-0477(1998)079<0061:APGTW A $>2.0 . \mathrm{CO} ; 2$. [Link]

Trouet, V. and G. J. van Oldenborgh, 2013: KNMI Climate Explorer: A web-based research tool for high-resolution paleoclimatology. Tree-Ring Res., 69, 3-13, doi: 10.3959/1536-1098-69.1.3. [Link]

Tuanmu, M.-N., A. Viña, J. A. Winkler, Y. Li, W. Xu, Z. 
Ouyang, and J. Liu, 2013: Climate-change impacts on understorey bamboo species and giant pandas in China's Qinling Mountains. Nat. Clim. Change, 3, 249-253, doi: 10.1038/nclimate1727. [Link]

Wang, L., J. Duan, J. Chen, L. Huang, and X. Shao, 2009: Temperature reconstruction from tree-ring maximum density of Balfour spruce in eastern Tibet, China. Int. J. Climatol., 30, 972-979, doi: 10.1002/joc.2000. [Link]

Wang, S., J. Zhu, and J. Cai, 2004: Interdecadal variability of temperature and precipitation in China since 1880. Adv. Atmos. Sci., 21, 307-313, doi: 10.1007/ BF02915560. [Link]

Wigley, T. M. L., K. R. Briffa, and P. D. Jones, 1984: On the average value of correlated time series, with applications in dendroclimatology and hydrometeorology. $J$. Clim. Appl. Meteorol., 23, 201-213, doi: 10.1175/15200450(1984)023<0201:OTAVOC>2.0.CO;2. [Link]

Wu, J.-G. and J.-J. Lv, 2009: Potential Effects of Climate Change on the Distributions of Giant Panda (Ailuropoda Melanoleuca) in China. Environ. Sci. Tech., 32,
168-177, doi: 10.3969/j.issn.1003-6504.2009.12.040. (in Chinese) [Link]

Wu, P., L. Wang, and X. Shao, 2008: Reconstruction of summer temperature variation from maximum density of alpine pine during 1917-2002 for west Sichuan Plateau, China. J. Geogr. Sci., 18, 201-210, doi: 10.1007/ s11442-008-0201-7. [Link]

Wu, X., Z. Lin, and L. Sun, 1988: A preliminary study on the climatic change of the Hengduan Mountains area since 1600 A.D.. Adv. Atmos. Sci., 5, 437-443, doi: 10.1007/BF02656789. [Link]

Yadav, R. R., W. K. Park, J. Singh, and B. Dubey, 2004: Do the western Himalayas defy global warming? Geophys. Res. Lett., 31, L17201, doi: 10.1029/2004GL020201. [Link]

Yu, S.-L., Y.-J. Yuan, W.-S. Wei, T.-W. Zhang, H.-M. Shang, and F. Chen, 2012: Reconstructed mean temperature in Mearkang, West Sichuan in July and its detection of climatic period signal. Plateau Meteorol., 31, 193-200. 